\title{
Visualization of the Vascular Course from the Right Atrium through the SVC to the Azygous Vein on ${ }^{18}$ FDG-PET/CT
}

Intravascular extension of malignancy is rare. Some cases of this have been reported, and these have mostly been seen in cases of lung cancer with extension into the pulmonary vein and left atrium. This is the first case of tumor involvement from the right atrium through the SVC to the azygous vein of the diaphragm level and all this was clearly visualized on ${ }^{18} \mathrm{FDG}-\mathrm{PET} / \mathrm{CT}$. A 68-year-old man was admitted for evaluation of SVC syndrome. Chest CT showed that the SVC was near completely obstructed by extension of tumor that had first invaded the thoracic spine and azygous vein. Multiple enlarged mediastinal lymph nodes were also noted. The pathologic examination of the biopsied tissues made the diagnosis of sarcomatoid carcinoma. The high metabolic activity within a thrombus on ${ }^{18} \mathrm{FDG}-\mathrm{PET} / \mathrm{CT}$ has been suggested to indicate tumor thrombus because a blood thrombus typically shows lower metabolic activity that's caused by incorporated fibroblasts and endothelial cells within the thrombus (1). However, because some reports demonstrated that a high FDG uptake could also occur in a blood thrombus (2), the exact differentiation of the two by ${ }^{18} \mathrm{FDG}-\mathrm{PET} / \mathrm{CT}$ seems to be difficult. ( $\mathrm{J}$ Lung Cancer 2009;8(1):34-35)

Key Words: Lung neoplasms, Tumor thrombus, Positron-emission tomography
Cheol Hyeon Kim, M.D. ${ }^{1}$ Du Hwan Choe, M.D. ${ }^{2}$ and Jae Cheol Lee, M.D.

Departments of ${ }^{1}$ Internal Medicine and ${ }^{2}$ Radiology, Korea Cancer Center Hospital, Seoul, Korea

Received: February 8, 2009

Accepted: March 4, 2009

\section{Address for correspondence} Jae Cheol Lee, M.D.

Department of Internal Medicine, Korea Cancer Center Hospital, 215-4, Gongneung-dong, Nowon-gu, Seoul 139-706, Korea

Tel: $82-2-970-1206$

Fax: $82-2-970-2438$

E-mail: jclee@kcch.re.kr
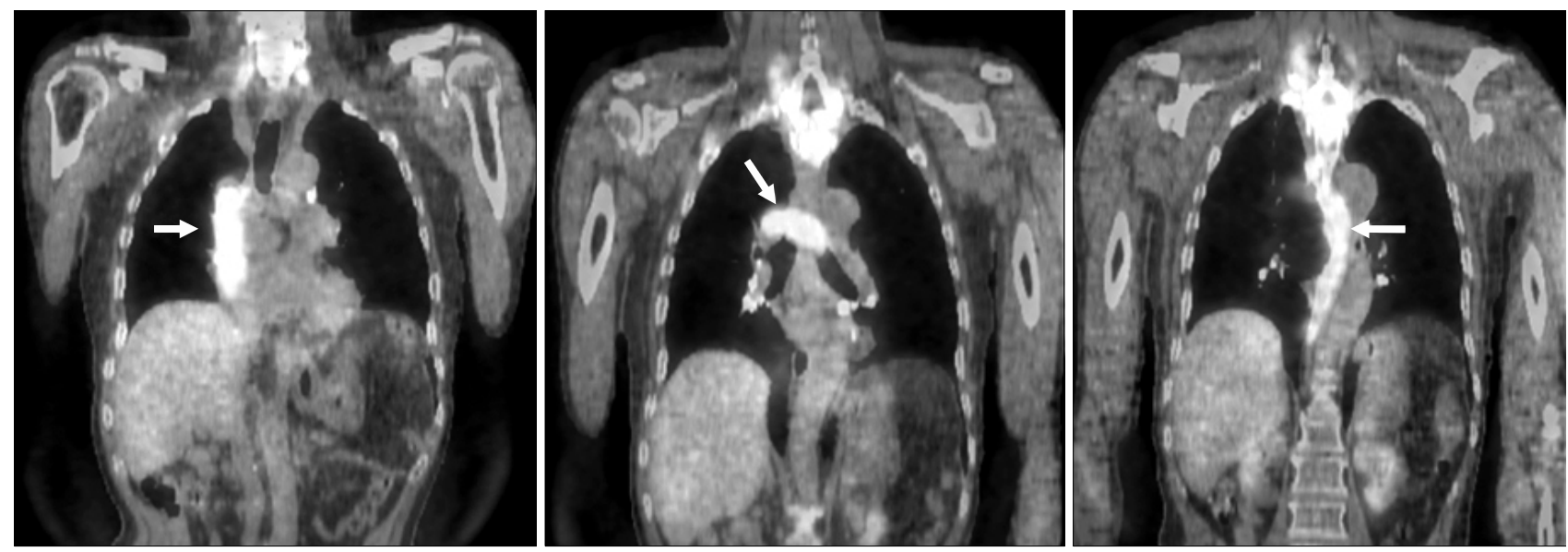

Fig. 1. ${ }^{18} \mathrm{FDG}-\mathrm{PET} / \mathrm{CT}$ showed the vascular course from the right atrium through the SVC to the azygous vein at the diaphragm level (arrows). The metabolic activity of the intraluminal lesions (SUV; 11.1) was higher than that of the tumor that had invaded the thoracic spines (SUV; 8.6). 


\section{REFERENCES}

1. Pitman AG, Solomon B, Padmanabhan R, McKenzie AF, Hicks RJ. Intravenous extension of lung carcinoma to the left atrium: demonstration by positron emission tomography with CT correlation. Br J Radiol 2000;73:206-208.

2. Ryan M. Deep venous thrombosis in the deep posterior compartment of the lower limb: PET CT FDG findings. Clin Nucl Med 2008;33:582-584. 